\title{
BMJ Open Development of a longlist of healthcare quality indicators for physical activity of patients during hospital stay: a modified RAND Delphi study
}

Niek Koenders, ${ }^{1}$ Stein van den Heuvel, ${ }^{1}$ Shanna Bloemen, ${ }^{1}$ Philip J van der Wees, ${ }^{2}$ Thomas J Hoogeboom ${ }^{2}$

To cite: Koenders $\mathrm{N}$, van den Heuvel S, Bloemen S, et al. Development of a longlist of healthcare quality indicators for physical activity of patients during hospital stay: a modified RAND Delphi study. BMJ Open 2019;9:e032208. doi:10.1136/ bmjopen-2019-032208

- Prepublication history and additional material for this paper are available online. To view these files, please visit the journal online (http://dx.doi org/10.1136/bmjopen-2019032208).

Received 07 June 2019 Revised 25 September 2019 Accepted 16 0ctober 2019

Check for updates

(c) Author(s) (or their employer(s)) 2019. Re-use permitted under CC BY-NC. No commercial re-use. See rights and permissions. Published by BMJ.

${ }^{1}$ Department of RehabilitationPhysical Therapy, Radboud Institute for Health Sciences, Radboud University Medical Center, Nijmegen, The Netherlands

${ }^{2} \mathrm{IQ}$ Healthcare, Radboud Institute for Health Sciences, Radboud University Medical Center, Nijmegen, Netherlands

Correspondence to

MSc. Niek Koenders;

niek.koenders@radboudumc.nl

\section{ABSTRACT}

Objective To develop a longlist of healthcare quality indicators for the care of hospitalised adults of all ages with (or at risk of) low physical activity during the hospital stay.

Design A modified RAND/UCLA Appropriateness Method Delphi study.

Setting and participants Participants were physical therapists, nurses and managers working in Dutch university medical centres.

Methods The current study consisted of three phases. Phase I was a systematic literature search for quality indicators and relevant domains. Phase II was a survey among healthcare professionals to collect additional data. Phase III consisted of three consensus rounds. In round 1 , experts rated the relevance of the potential indicators online (Delphi). The second round was a faceto-face expert panel meeting managed by an experienced moderator. Acceptability, feasibility and validity of the quality indicators were discussed by the panel members. In round 3, the panel members rated the relevance of the potential indicators that were still under discussion.

Results The search retrieved 1556 studies of which 53 studies were assessed full text. Data from 17 studies were included in a first draft longlist of indicators. Eighteen nurses and one physical therapist responded to the survey and added data for a second draft of the longlist. Experts constructed the final longlist of 23 indicators in three consensus rounds. Seven domains were identified: 'Policy', 'Attitude and education', 'Equipment and support', 'Evaluation', 'Information', 'Patient-tailored physical activity plan' and 'Outcome measure'.

Conclusion and implications The healthcare quality indicators developed in this study could help to grade, monitor and improve healthcare for hospitalised adults of all ages with (or at risk of) low physical activity during the hospital stay. Future research will focus on the psychometric quality of the indicators and selection of key performance indicators.

\section{INTRODUCTION}

Low physical activity of patients during the hospital stay has been extensively reported, ${ }^{1}$ especially in older patients. ${ }^{3-5}$ Low physical activity is a global healthcare issue with known

\section{Strengths and limitations of this study}

- The current study consists of a systematic review with duplicate study selection, an extra survey in healthcare professionals and three consensus rounds with a panel meeting.

- The panel meeting has been moderated by an internationally experienced moderator.

- The longlist of healthcare quality indicators was developed by a multidisciplinary group of healthcare professionals including nurses, physical therapists and managers.

- Only five panel members participated in the second and third consensus rounds.

- There were no patients and public involved in the coproduction of this study.

adverse effects such as decreased strength, functional decline, a prolonged hospital stay and institutionalisation. ${ }^{6-9}$ Common barriers to physical activity during the hospital stay include symptoms (ie, fatigue and pain), lack of motivation, medical devices and the hospital environment. ${ }^{10-13}$ Several quality improvement initiatives have been developed to improve physical activity of patients during the hospital stay. ${ }^{14-18}$ Nevertheless, quality indicators to measure the results of such quality improvement strategies are scarce. ${ }^{19-21}$

Healthcare quality indicators, also known as performance indicators or quality measures, are used all over the world to quantify, grade, monitor and improve the quality of healthcare. ${ }^{22-24}$ Recently, qualitative indicators have also been introduced to express matters that are hard to capture quantitatively such as having confidence in being safe in a community. ${ }^{25}$ Quality indicators are used in hospital care to provide information for quality improvement initiatives to, for example, decrease hospital mortality and complications. $^{26} 27$ Regarding the management of 
(low) physical activity of patients during the hospital stay, quality indicators could be helpful to capture persisting barriers in an attempt to improve the physical activity of all patients. ${ }^{28}$ As a first step, a longlist of relevant quality indicators is needed to serve as a database for healthcare professionals, clinical teams and organisations to measure performance for quality improvement purposes. ${ }^{21}$ Therefore, the aim of this study is to develop a longlist of quality indicators for the healthcare in hospitalised adults of all ages with (or at risk of) low physical activity during the hospital stay.

\section{METHODS \\ Design and setting}

A modified RAND/UCLA Appropriateness Method Delphi study ${ }^{29}$ was used to develop a longlist of quality indicators which meets the requirements of the Appraisal of Guidelines for Research and Evaluation (AGREE) II Healthcare Quality Indicator tool. ${ }^{30}$ The AGREE II tool was used as a guiding checklist for study development (online supplementary table A1). The reporting of this study followed guidelines of the Standards for QUality Improvement Reporting Excellence (SQUIRE 2.0). ${ }^{31}$ The study was conducted as a quality improvement initiative of the Radboud University Medical Center and followed the principles of the Declaration of Helsinki ${ }^{32}$ and Good Clinical Practice Guideline. ${ }^{33}$ Full ethical consideration was waived by the Ethics Committee of the Radboud University Medical Center in accordance with the Dutch Medical Research with Human Subjects Law.

All phases from the RAND/UCLA method were followed (figure 1). Phase I was a systematic literature search to identify indicators and relevant topics for potential indicators. Phase II was an extra survey among healthcare professionals to provide additional relevant topics. This extra survey was a modification to the original RAND/ UCLA method to obtain as many relevant indicators and topics as possible. Phase III consisted of three consensus rounds in which potential indicators were rated for their relevance by experts.

\section{Literature search}

The literature search was conducted to develop the first draft of a longlist of quality indicators for physical activity of hospitalised adults of all ages. CINAHL, MEDLINE and EMBASE were systematically searched for studies up to 24 January 2018 using a predefined search strategy (online supplementary table A2). The search strategy was compiled with the help of an experienced librarian (OYC). The study selection and data extraction were independently performed by two researchers (NK, $\mathrm{SvdH}) .{ }^{34}$ An indicator was considered relevant if a definition, numerator and denominator were described in the literature and related to physical activity of patients during the hospital stay. A topic was considered relevant when information in the text of articles commented on the physical activity of patients during the hospital stay.

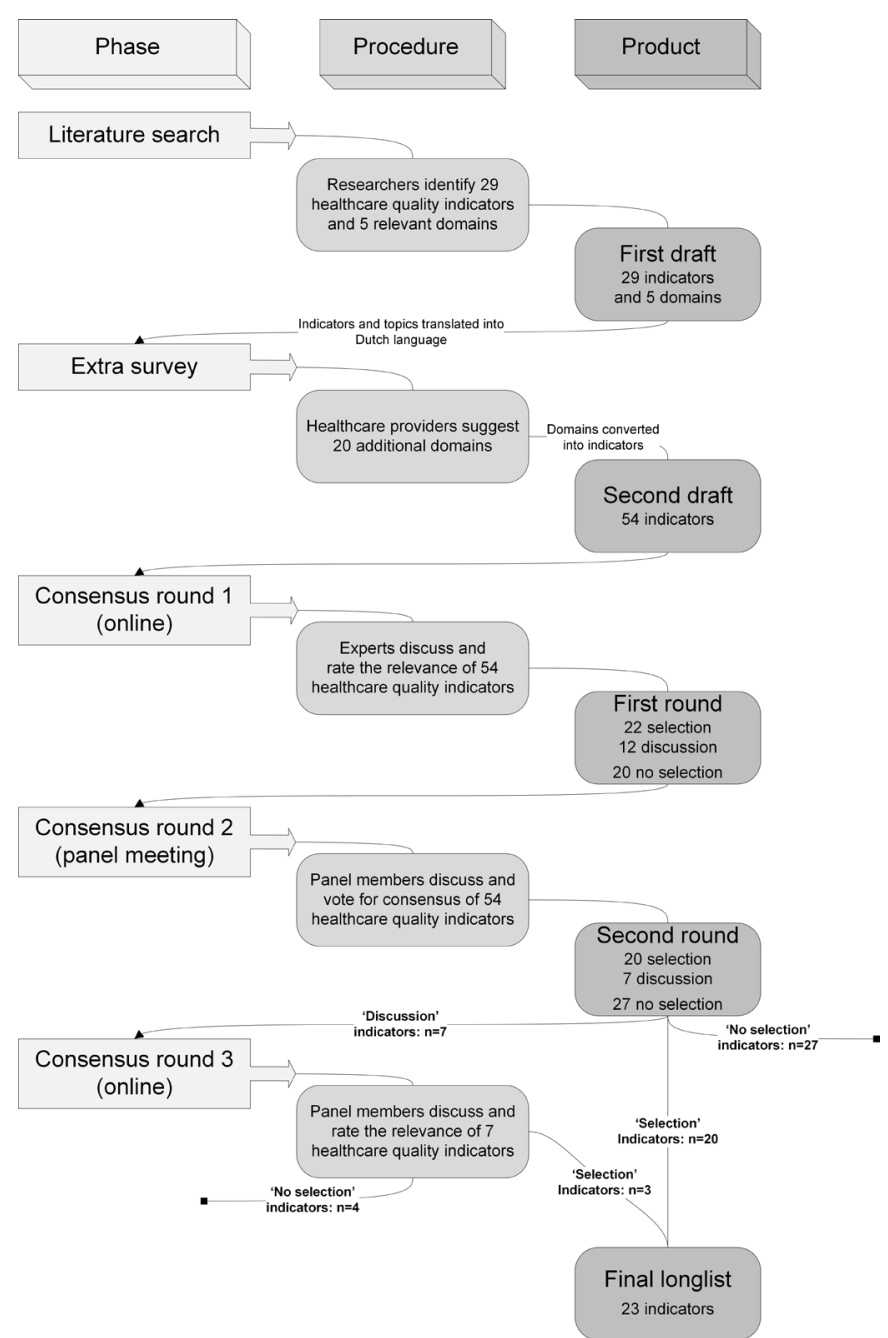

Figure 1 Flow diagram showing the selection of healthcare quality indicators in all phases of the study.

\section{Extra survey}

All indicators and topics were then translated into the Dutch language and presented to a convenience sample of healthcare professionals and managers of one Dutch academic hospital using an online questionnaire in LimeSurvey. ${ }^{35}$ The participants were requested to suggest additional topics related to physical activity of hospitalised adults of all ages. Furthermore, problems as a result of unclear translation or unclear formulation were solved with the help of the participants. The second draft was constructed by two researchers (NK, SvdH) with quality indicators from both the literature review and additional input from healthcare professionals and managers. Each topic was converted into an indicator by formulating a definition, numerator and denominator. All converted topics were checked for loss of information due to the translation by a third researcher $(\mathrm{TJH})$.

\section{Consensus rounds}

The second draft of the longlist of quality indicators was presented for relevance rating in the three consensus rounds with experts. ${ }^{36}$ To include a group of multidisciplinary experts in the consensus rounds, we purposefully 
sampled national experts. ${ }^{37}$ The multidisciplinary expert panel consisted of 28 experts (12 physical therapists, 11 nurses, 5 managers). All experts worked in a university medical centre (secondary care); participated in care, research and innovation of physical activity in patients during the hospital stay; and were representatives of an acknowledged national workgroup called Moving Hospitals (in Dutch: Beweegziekenhuizen). The experts were approached by email and telephone for participation in this study.

In the first consensus round (Delphi method), the experts received the longlist of quality indicators online in LimeSurvey. All indicators were rated on relevance by 14 experts for the first consensus label: selection, discussion or no selection. In the second round, all quality indicators were discussed in a panel meeting with five experts (panel members) moderated by an experienced moderator $(\mathrm{PvdW})$. First, the panel members discussed the acceptability to healthcare professionals and managers, the feasibility of use, and the validity in terms of providing more appropriate care and optimising patient outcomes. ${ }^{29}$ Finally, all panel members voted (yes or no) for final consensus on selection, discussion or no selection of the quality indicators. A methodologist (TJH) observed the panel meeting from the side-line and intervened if methodological errors occurred. In the third consensus round (Delphi method), all five panel members received the modified quality indicators and the quality indicators which were still under discussion online in LimeSurvey for final consensus.

\section{Data analysis}

The experts were instructed to rate the quality indicators only on relevance, not on, for example, feasibility or reliability. The relevance was scored using a 9-point Likert scale ranging from 1 not relevant to 9 very relevant. Consensus outcomes from the relevance ratings were calculated using the $I Q$ healthcare consensus tool. ${ }^{38}$ The consensus outcomes were based on the median score and the highest tertile, which resulted in labels selection, discussion or no selection (table 1). ${ }^{38}$ Quality indicators were labelled selection when the median score was $\geq 8$ on the 9-point Likert scale and $\geq 70 \%$ of the responses were in the highest tertile. The label discussion was given as a

Table 1 Labels corresponding to the consensus outcomes following different quantitative relevance ratings of experts in the consensus rounds using the IQ healthcare consensus tool

\begin{tabular}{llll} 
& & $\begin{array}{l}\geq \mathbf{3 0} \% \text { in the } \\
\text { lowest tertile } \\
\text { and } \mathbf{3 0} \% \text { in } \\
\text { the highest } \begin{array}{l}<0 \% \text { in } \\
\text { the highest } \\
\text { tertile }\end{array}\end{array}$ & $\begin{array}{l}\text { tertile } \\
\text { tertile }\end{array}$ \\
\hline Median $\leq 3$ & Discussion & Discussion & No selection \\
\hline Median $4 \leq 7$ & Discussion & Discussion & No selection \\
Median $\geq 8$ & Selection & Discussion & Discussion \\
\hline
\end{tabular}

result of three possible outcomes: (1) the median score was $\geq 8$ though less than $70 \%$ of the responses were in the highest tertile, (2) the median score was $<8$ though more than $70 \%$ of the responses were in the highest tertile, or (3) $30 \%$ of the responses were in the lowest and highest tertile. An indicator was labelled no selection when the median was $\leq 7$ and less than $70 \%$ of the responses were in the highest tertile.

In the second consensus round (panel meeting), five panel members received information on all first-round outcomes with corresponding labels per quality indicator. The panel members voted yes or no for final selection, discussion or no selection, and consensus meant that at least $75 \%$ of the members voted for one outcome. Where needed, the quality indicators were modified to improve the concise formulation. If modification(s) were suggested, the quality indicators were reformulated and rated (online and anonymous) for a second time by the panel members. The quality indicators needing further discussion were modified and rated by the same five panel members in the third online consensus round. After the third consensus round, quality indicators which were labelled selection were included in the longlist of quality indicators. All selected quality indicators were charted by domain and translated into the English language with a standardised forward-backward method by the Language Centre of the HAN University of Applied Sciences, Nijmegen, the Netherlands.

\section{Patient and public involvement}

No patients or public were involved in the design and conceptualisation of this study.

\section{RESULTS}

\section{Literature search}

The systematic literature search retrieved a total of 1556 studies, including 8 studies through searching the grey literature (online supplementary table A2 and figure A1). Full-text articles of 53 studies were assessed for eligibility, resulting in the inclusion of 17 articles. $^{1-3} 6$ 19-21 $39-48$ Data extraction resulted in the identification of 29 unique indicators and 5 domains related to hospitalised adults of all ages with (or at risk of) low physical activity during hospital stay for a first draft longlist of quality indicators.

\section{Extra survey}

The 29 indicators and 5 domains were translated into the Dutch language and surveyed among 296 healthcare professionals. Eighteen nurses and one physical therapist responded, and they suggested 20 additional domains. Twenty-five domains were reformulated and converted into indicators, resulting in 54 unique indicators in the second draft longlist of quality indicators (online supplementary table A3). 


\section{Consensus rounds}

Consensus round 1-Twenty-eight experts were invited to participate in the first online Delphi round. Fourteen experts responded: eight physical therapists, four nurses and two managers. A total of 22 indicators were labelled selection, 12 indicators discussion and 20 indicators no selection as a result of the first round. A detailed overview of ratings and selections is provided in online supplementary table A4.

Consensus round 2-The panel meeting lasted 3 hours with a total of five panel members: four physical therapists and one nurse. At the start, the moderator asked to discuss two key issues which were identified in the first Delphi round. First, the concept of physical activity during hospital stay was discussed and defined for the panel meeting as "an active transfer of a body(part) by a hospitalized patient". This did not include exercises or a transfer of a body(part) using a machine or object such as a standing aid or hospital bed. Second, the physical activity plan was defined as "an object in which physical activity should be reported, tailored at individual patients' needs, with a specific structure stating personal goals, frequency, intensity, time, and type of physical activity. Besides, the amount of support needed for mobilization should be described, for example, the need for a walking aid". Of all 22 indicators with the label selection, the panel members voted consensus for selection of 15 indicators, discussion of 5 indicators and no selection of 2 indicators. Of all 12 indicators with the label discussion, the panel members voted consensus for selection of 5 indicators, discussion of 1 indicator and no selection of 6 indicators. Of all 20 indicators with the label no selection, the panel members voted consensus for discussion of 1 indicator and no selection of 19 indicators. As a result of the second consensus round, 20 indicators were selected, 7 indicators remained under discussion and were included in round 3 , and 27 indicators were not selected (online supplementary table A4).

Consensus round 3 (Delphi)-In the third round, the same five panel members performed the final rating of seven remaining indicators resulting in the selection of three indicators, discussion of three indicators and no selection of 1 indicator. The discussion remained for three indicators (numbers 30, 32, 47) resulting in no selection due to a lack of consensus (online supplementary table A4). A flow diagram of the quality indicators selection is presented in figure 1 .

\section{Final longlist indicators}

The final longlist of quality indicators includes 23 indicators within 7 domains (table 2). The first domain, 'Policy', includes two structure indicators to evaluate institutional characteristics of the hospital ward. The second domain, 'Attitude and education', describes four structure indicators to assess the attitude and education of physicians and nurses related to physical activity stimulation. The third domain consists of three structure indicators and one process indicator on 'Equipment and support' to assess, for example, the availability of walking aids and ergometers. The fourth domain, 'Evaluation', includes five process indicators on the evaluation of freedomlimiting and mobility-limiting equipment (such as five-point fixation, intravenous lines and urinary catheters), physical functioning of patients and timely documentation of falls by a healthcare professional. The fifth domain, 'Information on physical activity', consists of two process indicators related to the provision of educational information to both patients and close-relatives. The sixth domain, 'Patient-tailored physical activity plan', includes three process indicators to assess the use and follow-up of a patient-tailored physical activity plan that 'should be reported, tailored at individual patients' needs, with a specific structure stating personal goals, frequency, intensity, time, and type of physical activity'. The seventh domain, 'Outcome measure', consists of three outcome indicators to measure if patients are physically active within 48 hours after hospital admission, if patients perform physical activities as described in a physical activity plan and whether patients have an acceptable degree of pain.

\section{DISCUSSION}

The current study presents the development of a longlist of quantitative and qualitative healthcare quality indicators for the healthcare of hospitalised adults of all ages with (or at risk of) low physical activity during the hospital stay. A multidisciplinary expert panel agreed on a list of 23 quality indicators with important domains such as an aim, patient-tailored physical activity plan, evaluation of physical activity, information on physical activity, equipment to stimulate physical activity, policy regarding physical activity and attitude related to physical activity. The quality indicators involve several stakeholders such as patients, close relatives and healthcare professionals (ie, physical therapists, nurses and physicians), which is consistent with the multifactorial nature of low physical activity of patients during the hospital stay. ${ }^{39}$

Reviewing current literature related to indicator development in secondary healthcare shows several studies reporting on physical activity of the elderly people. ${ }^{19-21}$ In contrast to our study, none of these aimed to evaluate physical activity in hospitalised adults of all ages during the hospital stay. Bail and Grealish ${ }^{19}$ performed a literature review and constructed a theoretical framework called 'Failure to maintain'. This study suggested quality indicators on physical environment factors and process factors (treatment and regimes that may affect the patient) to increase physical activity in complex older patients and ultimately decrease the incidence of urinary tract infections, pneumonia, delirium and pressure injuries. Arora $e t a l^{20}$ also performed a literature review for the general medical care of hospitalised vulnerable elderly people. Out of 30 reported quality indicators, only two related to physical activity of patients during the hospital stay: mobilisation and inpatient fall evaluation. These two domains are likely to be important, although two quality indicators do not completely address the complex issue of low physical activity in patients during the hospital stay. ${ }^{10}$ Tropea et $a t^{21}$ performed a Delphi study with anonymous 
Table 2 Final longlist of healthcare quality indicators for the care of patients with (or at risk of) low physical activity during the hospital stay

\begin{tabular}{|c|c|}
\hline Domain & Healthcare quality indicators \\
\hline \multicolumn{2}{|l|}{ 1. Policy } \\
\hline Title: & $\begin{array}{l}\text { 1. The hospital ward should have the policy to improve the physical activity of patients } \\
\text { (Structure indicator) }\end{array}$ \\
\hline Numerator: & The hospital ward policy was to inform patients to be physically active during the hospital stay \\
\hline Denominator: & The hospital ward \\
\hline Numerator: & $\begin{array}{l}\text { The hospital ward policy was to inform close relatives of patients about the importance of physical activity } \\
\text { during the hospital stay }\end{array}$ \\
\hline Denominator: & The hospital ward \\
\hline
\end{tabular}

2. Attitude and education

Title: $\quad 3$. Physicians should stimulate the physical activity of patients (Structure, qualitative indicator)

Numerator: $\quad$ The number of physicians who had a stimulating attitude towards the physical activity of patients during the hospital stay

Denominator: The number of physicians at the hospital ward Adapted from Inouye et $\mathrm{al}^{44}$ and Sourdet et $\left.a\right|^{40}$

Title: $\quad$ 4. Nurses should stimulate the physical activity of patients (Structure, qualitative indicator)

Numerator: The number of nurses who had a stimulating attitude towards the physical activity of patients during the hospital stay

Denominator: The number of nurses at the hospital ward Adapted from Inouye et $a l^{44}$ and Sourdet et $a l^{40}$

Title: $\quad$ 5. Nurses should stimulate independent functioning in daily activities of patients (Structure, qualitative indicator)

Numerator: $\quad$ The number of nurses who had a stimulating attitude towards independent physical functioning in daily activities of patients during the hospital stay

Denominator: The number of nurses at the hospital ward Adapted from Sourdet et $a{ }^{40}{ }^{40}$ Pedersen et $a l^{1}$ and Brown et $a l^{3}$

Title: $\quad$ 6. Nurses should have followed education related to physical activity of patients (Structure indicator)

Numerator: $\quad$ The number of nurses who followed education concerning the importance of physical activity of patients during the hospital stay

Denominator: The number of patients at the hospital ward

Adapted from Bail and Grealish ${ }^{19}$

3. Equipment and support

Title: $\quad$ 7. Patients should have adequate walking aids

\section{(Structure indicator)}

Numerator: $\quad$ The number of patients who were advised to use (a) walking aid(s), with (an) adequate walking aid(s) available

Denominator: The number of patients at the hospital ward who were advised to use (a) walking aid(s) Expert opinion

Title:

8. The hospital ward should provide adequate resources to stimulate physical activity (Structure indicator)

Numerator: The hospital ward provided physical activity stimulating resources. Examples are walking routes, treadmills, ergometers 
Table 2 Continued

\begin{tabular}{ll}
\hline Domain & Healthcare quality indicators \\
\hline Denominator: & The hospital ward \\
& Adapted from Bail and Grealish ${ }^{19}$ and Covinsky et a/ ${ }^{39}$
\end{tabular}

Title:

9. The hospital ward should have orientation promoting resources (Structure indicator)

Numerator: The hospital ward provided orientation stimulating resources. Examples are maps, direction signs, banners with route information

$\begin{array}{ll}\text { Denominator: } & \text { The hospital ward ward } \\ & \text { Adapted from Bail and Grealish }{ }^{19} \text { and Covinsky et a }{ }^{39} \\ \text { Title: } & \text { 10. Patients should receive support for mobilisation }\end{array}$

(Process indicator)

Numerator: The number of patients who received the support of (at least) one person for mobilisation

Denominator: The number of patients at the hospital ward who needed the support of (at least) one person for mobilisation

\begin{tabular}{|c|c|}
\hline & Adapted from Growdon et a ${ }^{43}$ and Lafont et a $\left.\right|^{41}$ \\
\hline \multicolumn{2}{|l|}{ 4. Evaluation } \\
\hline Title: & $\begin{array}{l}\text { 11. Nurses should evaluate freedom-limiting equipment } \\
\text { (Process indicator) }\end{array}$ \\
\hline Numerator: & $\begin{array}{l}\text { The nurses performed a daily assessment of the use of freedom-limiting equipment. Examples are five-point } \\
\text { fixation, wheelchair tables and wheelchair brakes }\end{array}$ \\
\hline \multirow[t]{2}{*}{ Denominator: } & The number of nurses at the hospital ward \\
\hline & Adapted from Inouye et a $\left.\right|^{44}$ and Sourdet et $a l^{40}$ \\
\hline Title: & $\begin{array}{l}\text { 12. Nurses should evaluate mobility-limiting equipment } \\
\text { (Process indicator) }\end{array}$ \\
\hline Numerator: & $\begin{array}{l}\text { The nurses performed a daily assessment of the use of mobility-limiting equipment in patients. Examples } \\
\text { are intravenous lines, urinary catheters and oxygen tubes }\end{array}$ \\
\hline \multirow[t]{2}{*}{ Denominator: } & The number of nurses at the hospital ward \\
\hline & Adapted from Inouye et a $/^{44}$ and Sourdet et $a /^{40}$ \\
\hline Title: & $\begin{array}{l}\text { 13. Nurses or physical therapists should evaluate the preadmission physical ability } \\
\text { (Process indicator) }\end{array}$ \\
\hline Numerator: & $\begin{array}{l}\text { The number of patients in which the preadmission physical functioning was evaluated within } 24 \text { hours after } \\
\text { hospital admission }\end{array}$ \\
\hline \multirow[t]{2}{*}{ Denominator: } & The number of patients at the hospital ward \\
\hline & $\begin{array}{l}\text { Adapted from Brown et al, }{ }^{3} \text { Pedersen et al, }{ }^{1} \text { Lafont et al }{ }^{41} \text { Zisberg et al, }{ }^{6} \text { Covinsky et al, }{ }^{39} \text { Bail and } \\
\text { Grealish, }{ }^{19} \text { Arora et al, }{ }^{42} \text { Tropea et al, }{ }^{21} \text { and Counsell et al }{ }^{47}\end{array}$ \\
\hline Title: & $\begin{array}{l}\text { 14. Nurses or physical therapists should evaluate the mobility } \\
\text { (Process indicator) }\end{array}$ \\
\hline Numerator: & The number of patients in which the mobility was evaluated within 24 hours after hospital admission \\
\hline \multirow[t]{2}{*}{ Denominator: } & The number of patients at the hospital ward \\
\hline & Adapted from Covinsky et a ${ }^{39}$ \\
\hline Title: & $\begin{array}{l}\text { 15. Patients should be evaluated after a fall incident } \\
\text { (Process indicator) }\end{array}$ \\
\hline Numerator: & The number of patients in which a fall incident was evaluated within 24 hours after the fall \\
\hline \multirow[t]{2}{*}{ Denominator: } & The number of patients at the hospital ward with a fall incident \\
\hline & Adapted from Arora et $\mathrm{a}^{20}$ and Tropea et $\mathrm{a}^{2^{21}}$ \\
\hline \multicolumn{2}{|l|}{ 5. Information } \\
\hline Title: & $\begin{array}{l}\text { 16. Patients should be informed about the importance of physical activity } \\
\text { (Process indicator) }\end{array}$ \\
\hline
\end{tabular}

Continued 
Table 2 Continued

\begin{tabular}{ll}
\hline Domain & Healthcare quality indicators \\
\hline Numerator: & $\begin{array}{l}\text { The number of patients who were informed about the importance of physical activity during the hospital } \\
\text { stay }\end{array}$ \\
Denominator: & $\begin{array}{l}\text { The number of patients at the hospital ward } \\
\text { Adapted from Bail and Grealish }\end{array}$ \\
Title: & $\begin{array}{l}\text { 17. Close relatives of patients should be informed about the importance of physical activity } \\
\text { (Process indicator) }\end{array}$ \\
Numerator: & $\begin{array}{l}\text { The number of close relatives of patients who were informed about the importance of physical activity } \\
\text { during the hospital stay }\end{array}$ \\
Denominator: & The number of patients at the hospital ward with close relatives \\
& Adapted from Bail and Grealish
\end{tabular}

6. Patient-tailored physical activity plan

Title: $\quad$ 18. Patients should have a physical activity plan (Process indicator)

Numerator: The number of patients who had a physical activity plan within 48 hours after hospital admission

Denominator: The number of patients at the hospital ward Adapted from Growdon et $a l^{43}$ and Lafont et $a l^{41}$

Title: $\quad$ 19. Patients in need for support during mobilisation should have a physical activity plan (Process indicator)

Numerator: The number of patients, who needed the support of (at least) one person for mobilisation, with a physical activity plan

Denominator: The number of patients at the hospital ward who needed the support of at (least) one person for mobilisation

Adapted from Growdon et $a l^{43}$ and Lafont et al ${ }^{41}$

Title: $\quad$ 20. Patients without need for support during mobilisation should have a physical activity plan (Process indicator)

Numerator: The number of patients, who did not need the support of a person for mobilisation, with a physical activity plan. Patients who only use (a) walking aid(s) are considered independent

Denominator: The number of patients at the hospital ward who did not need the support of a person for mobilisation Adapted from Growdon et $a^{43}$ and Lafont et $a l^{41}$

7. Outcome measure

Title: 21. Patients should be physically active within 48 hours after hospital admission (Outcome indicator)

Numerator: The number of patients who were physically active within 48 hours after hospital admission

Denominator: The number of patients at the hospital ward

Adapted from Arora et a ${ }^{20}$

Title:

22. Patients should perform physical activities as described in their physical activity plan

(Outcome indicator)

Numerator: The number of patients who performed physical activities as described in their physical activity plan

Denominator: The number of patients at the hospital ward with a physical activity plan

$\begin{array}{ll}\text { Title: } & \begin{array}{l}\text { Adapted from Growdon et } \mathrm{al}{ }^{43} \text { and Lafont et } \mathrm{a} \mathrm{A}^{41} \\ \text { 23. Patients should have an acceptable degree of pain } \\ \text { (Outcome indicator) }\end{array} \\ \text { Numerator: } & \begin{array}{l}\text { The number of patients who scored pain at rest and pain during physical activities with a Numeric Pain } \\ \text { Rating Scale } \leq 4\end{array} \\ \text { Denominator: } & \text { The number of patients at the hospital ward } \\ & \text { Adapted from Sourdet et al }{ }^{40} \text { Covinsky et a }{ }^{39} \text { and Arora et al }{ }^{42}\end{array}$


voting rounds and a panel meeting similar to the current study, resulting in a set of quality indicators for healthcare in older hospitalised patients. The set exists of three quality indicator domains related to physical activity in patients during the hospital stay with five relevant quality indicators: inpatient fall evaluation, fall-related injuries including fractures, pressure ulcer risk assessment, discharge assessment and assessment of physical function.

Interestingly, the current study found two quality indicators with a focus on hospital ward policy. In line with the Medical Research Council recommendations, quality improvement studies which aim to improve physical activity in hospitalised adults of all ages should include the perspective of local hospital policy in their study development and process evaluation. ${ }^{49}$ Furthermore, qualitative quality indicators were described to evaluate the attitudes of healthcare professionals related to physical activity. Attitudes are often hard to measure and therefore underexposed in other studies, ${ }^{25}$ despite the knowledge that attitudes of different stakeholders play an important role in healthcare quality improvement. ${ }^{50}$ With low physical activity during hospital stay being a multifactorial issue in hospitalised adults of all ages, the current study provides crucial knowledge to evaluate healthcare for hospitalised adults of all ages (with or) at risk of low physical activity during the hospital stay.

\section{Strengths and limitations}

The current study has several strengths. First, all methods as suggested by the modified RAND/UCLA are followed in detail. The use of a thorough systematic review with duplicate study selection, an extra survey in healthcare professionals and consensus rounds with a panel meeting is considered as a very rigorous quality indicators development procedure. ${ }^{51}$ Second, the panel meeting has been moderated by an internationally experienced moderator (PvdW) which contributed to an efficient and systematic discussion of all quality indicators.

There are some limitations to the current study that need to be discussed. First, only five panel members participated in the panel meeting and the third consensus round which is lower than the preferred 7 to 15 members within the RAND/UCLA method. ${ }^{29}$ Despite the reduced diversity of representation, the smaller group size was found to stimulate the involvement of every panel member in the group discussion. Second, two items of the AGREE II were not met. ${ }^{30}$ The quality indicators were not submitted to external review, and stakeholders such as patients, managers and healthcare insurers were insufficiently included in the process of quality indicators development. However, the limited external review and stakeholder involvement could be adequately addressed in future research.

\section{Recommendations for future research}

As the next step of our quality improvement initiative, a multicentre study will be performed to assess the acceptability, feasibility and reliability of the longlist of quality indicators for the healthcare in hospitalised adults of all ages with (or at risk of) low physical activity during the hospital stay. The longlist of quality indicators will be applied in practice to further assess the acceptability to patients, healthcare professionals and managers, as well as its feasibility and reliability. ${ }^{52}$ Future research will include a validation study following the Delphi technique of Hasson et $a \tilde{l}^{51}$ in a team of national and international experts. This would provide crucial information on the appropriateness of care and optimisation of patient outcomes. To improve feasibility in daily practice, it would be useful to select approximately three or four key performance quality indicators from the current longlist. Ultimately, a quality improvement study should use the key performance quality indicators in daily healthcare and assess their effect on patient outcomes such as strength and functional decline.

\section{CONCLUSIONS AND IMPLICATIONS}

The healthcare quality indicators developed within the current study form a rigorous basis to evaluate healthcare for hospitalised adults of all ages with (or at risk of) low physical activity during the hospital stay. Improvements in healthcare related to low physical activity of patients during the hospital stay are urgently needed, as the epidemic of low physical activity has already existed for decades with known, well-reported adverse effects. Quality improvement projects to increase the physical activity of patients during the hospital stay using currently developed healthcare quality indicators are promising, relevant and will improve outcomes in hospitalised adults of all ages.

Acknowledgements We would like to thank librarian On Ying Chan for her help in the systematic literature search. Inge Janssen and Rebecca Cooke of the Language Centre (HAN University of Applied Sciences, Nijmegen, the Netherlands) are thanked for their forward-backward translation of the longlist of healthcare quality indicators. We would also like to thank Amy Awad-Sman for her language corrections. All members of the Dutch expert group Beweegziekenhuizen are thanked for their help in study conceptualisation and data collection.

Contributors All listed authors meet the ICMJE criteria for authorship. NK, SvdH, and TJH contributed to study conceptualization. Data collection and analysis was handled by NK, SvdH, PvdW, and TJH. SB provided resources and contributed to project administration. PvdW and TJH supervised all research activities. All authors reviewed concept drafts of the manuscript and approved submission of the final draft.

Funding The authors have not declared a specific grant for this research from any funding agency in the public, commercial or not-for-profit sectors.

Competing interests None declared.

Patient consent for publication Not required.

Provenance and peer review Not commissioned; externally peer reviewed.

Data availability statement All data relevant to the study are included in the article or uploaded as online supplementary information.

Open access This is an open access article distributed in accordance with the Creative Commons Attribution Non Commercial (CC BY-NC 4.0) license, which permits others to distribute, remix, adapt, build upon this work non-commercially, and license their derivative works on different terms, provided the original work is properly cited, appropriate credit is given, any changes made indicated, and the use is non-commercial. See: http://creativecommons.org/licenses/by-nc/4.0/.

\section{REFERENCES}

1 Pedersen MM, Bodilsen AC, Petersen J, et al. Twenty-four-hour mobility during acute hospitalization in older medical patients. $J$ Gerontol A Biol Sci Med Sci 2013;68:331-7. 
2 Mudge AM, McRae P, McHugh K, et al. Poor mobility in hospitalized adults of all ages. $J$ Hosp Med 2016;11:289-91.

3 Brown CJ, Redden DT, Flood KL, et al. The underrecognized epidemic of low mobility during hospitalization of older adults. J Am Geriatr Soc 2009;57:1660-5.

4 Warshaw GA, Moore JT, Friedman SW, et al. Functional disability in the hospitalized elderly. JAMA 1982;248:847-50.

5 Lazarus BA, Murphy JB, Coletta EM, et al. The provision of physical activity to hospitalized elderly patients. Arch Intern Med 1991:151:2452-6.

6 Zisberg A, Shadmi E, Sinoff G, et al. Low mobility during hospitalization and functional decline in older adults. J Am Geriatr Soc 2011;59:266-73.

7 Boyd CM, Landefeld CS, Counsell SR, et al. Recovery of activities of daily living in older adults after hospitalization for acute medical illness. J Am Geriatr Soc 2008;56:2171-9.

8 Baztán JJ, Suárez-García FM, López-Arrieta J, et al. Effectiveness of acute geriatric units on functional decline, living at home, and case fatality among older patients admitted to hospital for acute medical disorders: meta-analysis. BMJ 2009;338.

9 Van Ancum JM, Scheerman K, Jonkman NH, et al. Change in muscle strength and muscle mass in older hospitalized patients: a systematic review and meta-analysis. Exp Gerontol 2017;92:34-41.

10 Koenders N, van Oorsouw R, Seeger JPH, et al. 'I'm not going to walk, just for the sake of walking...': a qualitative, phenomenological study on physical activity during hospital stay. Disabil Rehabil 2018:1-8.

11 Chan DE-Y, Hong MLI, Tan MY-HG, et al. Older patients' participation in physical activity during hospitalization: a qualitative study of ward nurses' perceptions in an Asian context. Geriatr Nurs 2019;40:91-8.

12 Lam KK, Ho Cheung William L, Ho KYE, et al. Factors contributing to the low physical activity level for Hong Kong Chinese children hospitalised with cancer: an exploratory study. J Clin Nurs 2017:26:190-201.

13 Kneafsey R, Clifford C, Greenfield S. What is the nursing team involvement in maintaining and promoting the mobility of older adults in hospital? A grounded theory study. Int J Nurs Stud 2013;50:1617-29.

14 Liu B, Moore JE, Almaawiy U, et al. Outcomes of mobilisation of vulnerable elders in Ontario (MOVE ON): a multisite interrupted time series evaluation of an implementation intervention to increase patient mobilisation. Age Ageing 2018;47:112-9.

15 Oliver D. David Oliver: fighting pyjama paralysis in hospital wards. BMJ 2017;357:j2096.

16 Booth KA, Simmons EE, Viles AF, et al. Improving geriatric care processes on two medical-surgical acute care units: a pilot study. $J$ Healthc Qual 2019;41:23-31.

17 Teodoro CR, Breault K, Garvey C, et al. Step-up: study of the effectiveness of a patient ambulation protocol. Medsurg Nurs 2016;25:111-6.

18 Brown CJ, Foley KT, Lowman JD, et al. Comparison of posthospitalization function and community mobility in hospital mobility program and usual care patients: a randomized clinical trial. JAMA Intern Med 2016;176:921-7.

19 Bail K, Grealish L. 'Failure to maintain': a theoretical proposition for a new quality indicator of nurse care rationing for complex older people in hospital. Int J Nurs Stud 2016;63:146-61.

20 Arora VM, McGory ML, Fung CH. Quality indicators for hospitalization and surgery in vulnerable elders. J Am Geriatr Soc 2007;55(Suppl 2):S347-58.

21 Tropea J, Amatya B, Brand CA, et al. Use of consensus methods to select clinical indicators to assess activities to minimise functional decline among older hospitalised patients. Aust Health Rev 2011;35:404-11.

22 Petersson IF, Strömbeck B, Andersen L, et al. Development of healthcare quality indicators for rheumatoid arthritis in Europe: the eumusc.net project. Ann Rheum Dis 2014;73:906-8.

23 Steinke S, Beikert FC, Langenbruch A, et al. Measurement of healthcare quality in atopic dermatitis-development and application of a set of quality indicators. J Eur Acad Dermatol Venereol 2018;32:2237-43.

24 Bellmunt S, Roqué M, Osorio D, et al. Healthcare quality indicators of peripheral artery disease based on systematic reviews. Eur $J$ Vasc Endovasc Surg 2014;48:60-9.

25 Church C, Rogers MM. Designing for results: integrating monitoring and evaluation in conflict transformation programs: search for common ground. Washington, DC: Search for Common Ground, 2006.
26 Wright J, Dugdale B, Hammond I, et al. Learning from death: a hospital mortality reduction programme. $J R$ Soc Med 2006;99:303-8.

27 Haynes AB, Weiser TG, Berry WR, et al. A surgical safety checklist to reduce morbidity and mortality in a global population. N Engl J Med 2009;360:491-9.

28 Hoyer EH, Friedman M, Lavezza A, et al. Promoting mobility and reducing length of stay in hospitalized general medicine patients: a quality-improvement project. J Hosp Med 2016;11:341-7.

29 Fitch K, Bernstein SJ, Aguilar MD. The RAND/UCLA appropriateness method user's manual. Santa Monica, CA: Rand CORP, 2001

30 Abrahamyan L, Boom N, Donovan LR, et al. An international environmental scan of quality indicators for cardiovascular care. Can J Cardiol 2012;28:110-8.

31 Ogrinc G, Davies L, Goodman D, et al. SQUIRE 2.0 (Standards for QUality Improvement Reporting Excellence): revised publication guidelines from a detailed consensus process. BMJ Qual Saf 2016;25:986-92.

32 World Medical Association. World Medical Association Declaration of Helsinki: ethical principles for medical research involving human subjects. JAMA 2013;310:2191-4.

33 Grimes DA, Hubacher D, Nanda K, et al. The good clinical practice guideline: a bronze standard for clinical research. Lancet 2005;366:172-4.

34 Higgins JP, Green S. Cochrane handbook for systematic reviews of interventions. John Wiley \& Sons, 2011.

35 Schmitz N, Wang J, Malla A, et al. The impact of psychological distress on functional disability in asthma: results from the Canadian community health survey. Psychosomatics 2009;50:42-9.

36 Boulkedid R, Abdoul H, Loustau M, et al. Using and reporting the Delphi method for selecting healthcare quality indicators: a systematic review. PLoS One 2011;6:e20476.

37 Portney LG, Watkins M. Foundations of clinical research: applications to practice. FA Davis Company/Publishers, 2015.

38 Stienen JJC, Ouwens MMTJ, Pols MA, et al. Hoe kom je tot de kern van de zaak? TSG 2011;89:405-8.

39 Covinsky KE, Pierluissi E, Johnston CB. Hospitalization-associated disability: 'She was probably able to ambulate, but l'm not sure'. JAMA 2011;306:1782-93.

40 Sourdet S, Lafont C, Rolland Y, et al. Preventable iatrogenic disability in elderly patients during hospitalization. J Am Med Dir Assoc 2015;16:674-81.

41 Lafont C, Gérard S, Voisin T, et al. Reducing 'iatrogenic disability' in the hospitalized frail elderly. J Nutr Health Aging 2011;15:645-60.

42 Arora VM, Plein C, Chen S, et al. Relationship between quality of care and functional decline in hospitalized vulnerable elders. Med Care 2009;47:895-901.

43 Growdon ME, Shorr RI, Inouye SK. The tension between promoting mobility and preventing falls in the hospital. JAMA Intern Med 2017; $177: 759-60$.

44 Inouye SK, Brown CJ, Tinetti ME. Medicare nonpayment, hospital falls, and unintended consequences. $N$ Engl J Med 2009;360:2390-3.

45 Grube MM, Dohle C, Djouchadar D, et al. Evidence-based quality indicators for stroke rehabilitation. Stroke 2012;43:142-6.

46 Le H, Khankhanian P, Joshi N, et al. Patients recovering from abdominal surgery who walked with volunteers had improved postoperative recovery profiles during their hospitalization. World $J$ Surg 2014;38:1961-5

47 Counsell SR, Holder CM, Liebenauer LL, et al. Effects of a multicomponent intervention on functional outcomes and process of care in hospitalized older patients: a randomized controlled trial of acute care for elders (ACE) in a community hospital. J Am Geriatr Soc 2000;48:1572-81.

48 Fisher SR, Kuo Y-F, Sharma G, et al. Mobility after hospital discharge as a marker for 30-day readmission. J Gerontol A Biol Sci Med Sci 2013;68:805-10.

49 Craig P, Dieppe P, Macintyre S, et al. Developing and evaluating complex interventions: the new Medical Research Council guidance. BMJ 2008;337:a1655.

50 Wensing MJP, Grol R. Effectieve verbetering van de patiëntenzorg. Nederlands: Bohn Stafleu van Loghum, 2017.

51 Hasson F, Keeney S, McKenna H. Research guidelines for the Delphi survey technique. J Adv Nurs 2000;32:1008-15.

52 Campbell SM, Braspenning J, Hutchinson A, et al. Research methods used in developing and applying quality indicators in primary care. Qual Saf Health Care 2002;11:358-64. 